\title{
PELATIHAN MOULD LOFT (LANTAI GAMBAR) KAPAL BAGI PENGRAJIN/PEMBUAT KAPAL TRADISIONAL DI KABUPATEN BATANG - JAWA TENGAH
}

\author{
Parlindungan Manik ${ }^{1)}$, Deddy Chrismianto ${ }^{1)}$ \\ ${ }^{1)}$ Teknik Perkapalan, Fakultas Teknik, Universitas Diponegoro \\ Email : parlin1974@yahoo.com
}

\begin{abstract}
Abstrak
Kabupaten Batang yang merupakan wilayah pesisir mempunyai banyak potensi yang dapat dikembangkan menjadi aset yang berharga bagi bangsa yaitu para pengrajin/pembuat kapal tradisional. Para pengrajin ini mampu menghasilkan kapal tipe mini purse seine yang mampu berlayar dalam radius pelayaran 12 sampai dengan 200 mil laut. Kapal mini purse siene tipe Batang mempunyai karakteristik yang cukup baik karena mempunyai stabilitas kapal yang baik dan mesin utama diletakkan di dalam kamar mesin (inboard engine).

Kapal purse seine ini telah dibuat dan diproduksi secara turun-temurun dan jumlahnya sudah banyak di daerah Batang. Ukuran kapal yang diproduksi mulai dari 5 GT (Gross Tonage) sampai dengan 40 GT dengan harga sebesar 300 juta sampai dengan 2 miliar rupiah. Para pembuat kapal pada umumnya tidak atau kurang memiliki pengetahuan tentang gambar desain kapal dari kapal yang diproduksi. Belakangan ini telah dimulai oleh para pengguna yang mensyaratkan adanya gambar desain dan gambar - gambar kerja lainnya sehingga dituntut adanya tenaga kerja dan para pembuat kapal yang mampu membuat dan membaca gambar kapal.

Pada Program IbM ini dilaksanakan di CV. Laksana Abadi dan dan CV. Rizki Maulana Bahari yang bertujuan agar para pengrajin/pembuat kapal kayu tradisional di kabupaten Batang memiliki ketrampilan untuk menggambar bentuk badan kapal dalam skala 1:1 pada lantai gambar atau biasa disebut dengan istilah Mould Loft. Dengan tergambarnya bentuk badan kapal/konstruksi kapal dalam skala 1:1 maka akan didapat bentuk badan kapal yang akurat dan ukuran konstruksi kapal yang tepat, sehingga dalam proses pembangunannya segala ukuran yang terpakai sudah tepat dan tidak ada kesalahan bentuk maupun ukuran. Hal ini sangat diperlukan oleh pihak pelaksana, untuk menunjang kemudahan pelaksanaan dan kualitas hasil pekerjaan.

Pendekatan yang diterapkan dalam penerapan teknologi ini harus mencakup dua buah aspek yaitu : aspek kognitif dan psikomotorik. Pada aspek kognitif diharapkan bertambahnya pengetahuan peserta pelatihan, sehingga para pengrajin/pembuat kapal mampu melakukan proses mould loft pada lantai gambar. Sedangkan pada aspek psikomotorik diharapkan para peserta mampu menggunakan peralatan yang ada dalam membuat gambar kerja sebenarnya (skala $1: 1$ ) pada lantai gambar.
\end{abstract}

Kata Kunci : kapal, Batang, Mould loft

\section{PENDAHULUAN}

\subsection{Analisa Situasi}

Kabupaten Batang terletak di pantai utara Jawa Tengah. Luas daerah 788,642 km2. Batas-batas wilayahnya sebelah utara laut jawa, sebelah timur kabupaten Kendal, sebelah selatan kabupaten Wonosobo dan kabupaten Banjarnegara, sebelah barat kabupaten dan kodya pekalongan. Posisi tersebut menempatkan wilayah kabupaten batang, utamanya ibu kota pemerintahannya pada jalur ekonomi pulau jawa sebelah utara. Arus transportasi dan mobilitas yang tinggi di jalur pantura memberikan kemungkinan kabupaten batang berkembang cukup prospektif di sektor jasa transit dan transportasi. 


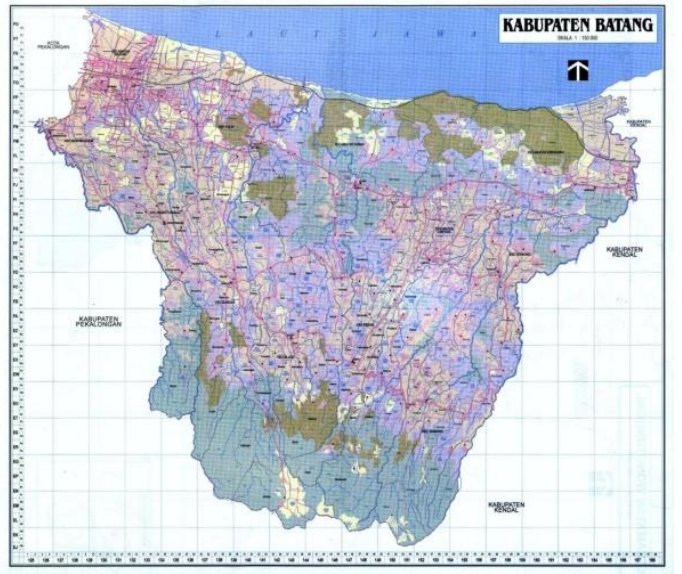

Gambar 1. Peta Kabupaten Batang

Jumlah penduduk Kabupaten Batang pada tahun 2011 adalah 713.942 jiwa yang terdiri dari 358.419 laki- laki dan 355.523 perempuan dengan pertumbuhan rata rata penduduk sejak tahun 2008 tercatat $1 \%$. Berarti pertumbuhan penduduk di Kabupaten Batang tergolong masih rendah. (Sumber : Badan Pusat Statistik Kab.Batang). Kepadatan penduduk di Kabupaten Batang pada tahun 2007 sebesar $2.783 \mathrm{~km}^{2}$ dengan kepadatan terbesar berada di Kecamatan Batang 3.181 $\mathrm{km}^{2}$, sedangkan kepadatan terkecil di Kecamatan Blado $559 \mathrm{~km}^{2}$.

Berdasarkan jumlah penduduk menurut kelompok umur, maka kelompok umur tertinggi adalah kelompok umur 10 - 14 tahun dengan jumlah penduduk 74.523 jiwa atau sekitar $10,79 \%$ dari seluruh jumlah penduduk yang ada. Sedangkan kelompok umur terkecil adalah kelompok umur 65 - 69 tahun dengan jumlah penduduk 13.977 jiwa atau 2,02\% dari seluruh jumlah penduduk pada Kabupaten Batang.

Struktur penduduk menurut tingkat pendidikan merupakan salah satu tolok ukur bagi kualitas sumberdaya manusia. Untuk itu perlu diketahui kondisi penduduk menurut pendidikan yang ada di Kabupaten Batang. Sesuai data BPS Propinsi Tahun 2007 tentang Rangkuman Data Penduduk Usia Sekolah yang ada jumlah penduduk di Kabupaten Batang menurut tingkat pendidikannya mencapai 108.076 penduduk atau $15,47 \%$ dari total jumlah penduduk kabupaten Batang (698.564 penduduk) yang terdiri dari 73.754 penduduk usia SD (7-12 tahun) dan 34.322 penduduk usia SMP (13-15) jiwa
Terlepas dari rendahnya tingkat pendidikan masyarakat, di wilayah pesisir kabupaten ini terdapat potensi yang dapat dikembangkan sehingga dapat menjadi aset yang berharga bagi bangsa yaitu para pembuat kapal tradisional. Para pengrajin ini mampu menghasilkan kapal tipe mini purse seine yang mampu berlayar dalam radius pelayaran 12 sampai dengan 200 mil laut. Kapal mini purse siene tipe Batang mempunyai karakteristik yang cukup baik karena mempunyai stabilitas kapal yang baik dan mesin utama diletakkan di dalam kamar mesin (inboard engine).

Kapal purse seine ini telah dibuat dan diproduksi secara turun-temurun dan jumlahnya sudah banyak di daerah Batang. Ukuran kapal yang diproduksi mulai dari 5 GT (Gross Tonage) sampai dengan 40 GT dengan harga sebesar 300 juta sampai dengan 2 miliar rupiah. Para pembuat kapal pada umumnya tidak atau kurang memiliki pengetahuan tentang gambar desain kapal dari kapal yang diproduksi. Belakangan ini telah dimulai oleh para pengguna yang mensyaratkan adanya gambar desain dan gambar - gambar kerja lainnya sehingga dituntut adanya tenaga kerja dan para pembuat kapal yang mampu membuat dan membaca gambar kapal.

Pada Program IbM ini akan dilaksanakan "Pelatihan Mould Loft (Lantai Gambar) Kapal bagi Pengrajin / Pembuat Kapal Tradisional di Kabupaten Batang Jawa Tengah" di CV. Laksana Abadi dan dan CV. Rizki Maulana Bahari yang bertujuan agar para pengrajin/pembuat kapal kayu tradisional di kabupaten Batang memiliki ketrampilan untuk menggambar bentuk badan kapal dalam skala 1:1 pada lantai gambar atau biasa disebut dengan istilah Mould Loft.

Mould loft adalah menggambar bentuk badan kapal dalam skala 1:1 pada lantai gambar, meliputi gambar seluruh gadinggading kapal dan perletakan senta, serta gambar bentangan dari pelat kapal. Dengan tergambarnya bentuk badan kapal/konstruksi kapal dalam skala 1:1 maka akan didapat bentuk badan kapal yang akurat dan ukuran konstruksi kapal yang tepat, sehingga dalam proses pembangunannya segala ukuran yang terpakai sudah tepat dan tidak ada kesalahan bentuk maupun ukuran. Hal ini sangat diperlukan oleh pihak pelaksana, untuk 
menunjang kemudahan pelaksanaan dan kualitas hasil pekerjaan.

Dari hasil penggambaran berupa bentuk-bentuk dan ukuran yang sebenarnya, akan dipindahkan dalam bentuk mal/template yang lengkap dengan data-data ukuran serta data-data yang lainnya, yang akan diserahkan ke bagaian fabrikasi untuk dibuatkan komponen-komponen sesuai bentuk dan ukuran pada template masing -masing. Dalam penggambaran bentuk badan kapal sesungguhnya, tidak selalu sepanjang ukuran kapal seluruhnya, terutama untuk daerah tengah (parallel middle body). Hal ini dilakukan untuk penghematan tempat, pekerjaan. Dapat pula gambar-gambar digambar secara menumpuk, untuk mengatasi kesulitan membaca gambar yang menumpuk maka digunakan warna cat yang berbeda.

\subsection{Perumusan Masalah}

Berdasarkan identifikasi dan pengamatan awal di lapangan terhadap para pengrajin / pembuat kapal di $\boldsymbol{C V}$. Laksana Abadi dan CV. Rizky Maulana Bahari yang menjadi objek Program Iptek bagi Masyarakat (IbM) ada banyak permasalahan yang harus segera ditangani antara lain, masalah managemen dan administrasi, lemahnya aksesbilitas ke lembaga lain, rendahnya kualitas tenaga kerja dalam hal membuat dan membaca gambar kapal dan gambar kerja.

Dari berbagai masalah yang dihadapi oleh mitra setelah dilakukan diskusi dengan seksama, maka yang menjadi perioritas yang harus ditangani adalah membuat gambar kapal dengan skala $1: 1$ pada lantai gambar (proses Mould loft) dan peningkatan kemampuan para pengrajin/pembuat kapal untuk membaca gambar kerja. Dengan demikian diharapkan dengan pelaksanaan program iptek ini diharapkan adanya peningkatan kualitas hasil produksi kapal kayu di kabupaten Batang.

\subsection{Letak/Lokasi Industri Mitra}

Pelaksanaan kegiatan pengabdian ini berlangsung di CV. Laksana Abadi dan CV. Rizky Maulana Bahari Kabupaten Batang, Jawa Tengah. Lokasi ini berjarak kurang lebih $93 \mathrm{Km}$ dari kota Semarang. Adapun denah tempat lokasi sebagai berikut:

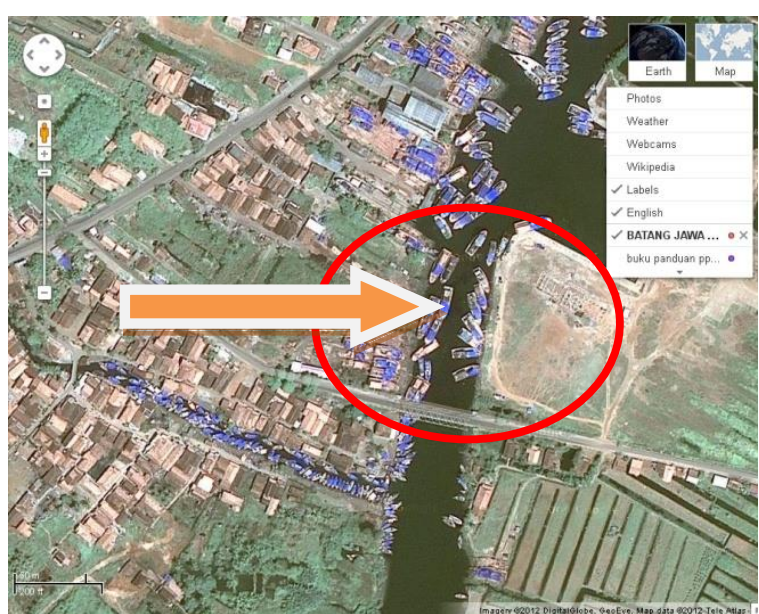

Gambar 2. Denah Lokasi Mitra

\section{TARGET DAN LUARAN}

Adapun target dan luaran dari pelaksaan program kegiatan $\mathrm{I}_{\mathrm{b}} \mathrm{M}$ ini adalah sebagai berikut:

\subsection{Pelatihan}

"Pelatihan Mould Loft (Lantai Gambar) Kapal bagi Pengrajin / Pembuat Kapal Tradisional di Kabupaten Batang - Jawa Tengah" sebagai Khalayak Sasaran, memiliki manfaat sebagai berikut :

1. Bertambahnya kemampuan dan ketrampilan para pengrajin/ pembuat kapal tradisional di CV. Laksana Abadi dan CV. Rizki Maulana Bahari dalam hal mould loft kapal pada lantai gambar yang meliputi :

a. Cara penggambaran Rencana Garis dengan ukuran sebenarnya ( skala 1:1)

b. Membuat garis bentuk gading pada body plan.

c. Membuat garis lengkung geladak melintang pada body plan.

d. Membuat garis lengkung geladak memanjang pada gambar pandangan samping (sheer plan).

2. Bertambahnya kemampuan dan ketrampilan para pengrajin/ pembuat kapal tradisional dalam hal membaca gambar kerja dalam pembangunan kapal, sehinnga mampu meningkatkan mutu dari produksi kapal yang dibangun. 


\subsection{Teknolgi Yang Ditawarkan}

Lantai gambar (Mould loft) adalah suatu media dimana seorang perancang kapal menggambar Rencana Garis dengan ukuran kapal yang sebenarnya ( skala 1:1 ). Lantai gambar ini sangat diperlukan di lapangan nantinya, karena di lantai gambar itu kita dapat megetahui gambaran kapal sesuai dengan ukuran sebenarnya.

a. Peralatan untuk Proses Mould loft

1. Rool Meter

2. Penggaris kayu

3. Penggaris siku

4. Mistar panjang

5. Pemberat/tindih

6. Mal kayu / mal kapal

7. Lantai gambar (ruangan untuk menggambar)

b. Bahan- Bahan yang dibutuhkan untuk Proses Mould loft

1. Triplek Melamin putih ukuran 2,4 $\mathrm{m} \mathrm{x}$ $1,2 \mathrm{~m}$ x $3 \mathrm{~mm}$ secukupnya (tempat mengambar)

2. Kapur warna

3. Spidol tiga warna

4. Aceton

5. Benang

6. Majun putih

c. Contoh Gambar Mal yang digunakan untuk proses moult loft

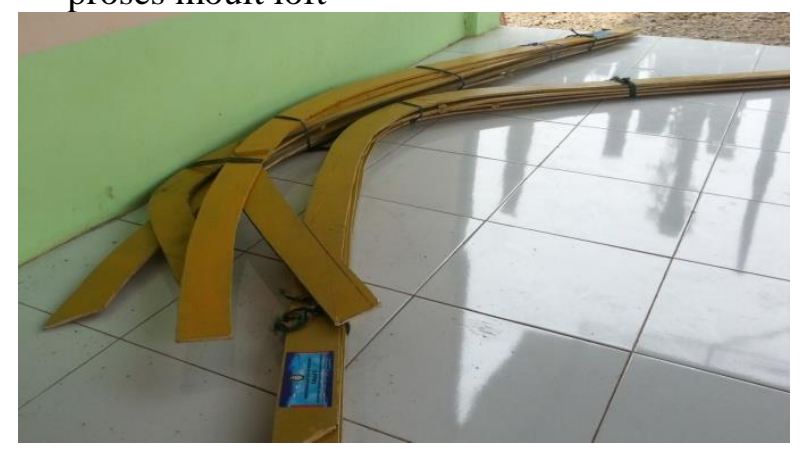

Gambar 3. Mal kayu

\section{METODE PELAKSANAAN}

3.1. Metode Pendekatan Yang Ditawarkan Untuk Mendukung Realisasi Program $\mathbf{I}_{\mathbf{b}} \mathbf{M}$

Pendekatan yang diterapkan dalam penerapan teknologi ini harus mencakup dua buah aspek yaitu : aspek kognitif dan psikomotorik. Pada aspek kognitif diharapkan bertambahnya pengetahuan peserta pelatihan, sehingga para pengrajin/pembuat kapal mampu melakukan proses mould loft pada lantai gambar. Sedangkan pada aspek psikomotorik diharapkan para peserta mampu menggunakan peralatan yang ada dalam membuat gambar kerja ke skala $1: 1$ pada lantai gambar.

Agar tercapai dua aspek tersebut maka metode yang dilakukan adalah terdiri dari beberapa tahap yaitu:

- Tahap pra pelatihan (preparing the entry behavior)

Pada tahap ini dilakukan seleksi dan penentuan kualifikasi peserta. Hal ini dilakukan agar pelatihan dapat berjalan sesuai dengan yang diharapkan. Selain itu juga dilakukan pre-test untuk mengukur pengetahuan peserta tentang teknik menggambar kapal dan membaca gambar kerja sebelum mengikuti pelatihan ini.

○ Tahap peningkatan pengetahuan mengenai Mould Loft (lantai gambar) kapal (improving knowledge)

Tahap knowledge improvement, ditujukan untuk meningkatkan pengetahuan peserta mengenai Mould loft (lantai gambar) kapal . Teknik instruksional yang digunakan pada tahap ini meliputi : ceramah dan diskusi kelompok

○ Tahap peningkatan ketrampilan mengenai Mould loft / lantai gambar kapal (improving reparation skill)

Tahap ini, lebih banyak memberikan waktu bagi peserta untuk berlatih cara menggambar kapal ke skala $1: 1$ pada lantai gambar. Latihan-latihan ini diberikan agar peserta lebih mahir dalam menggambar dan membaca gambar kerja pada lantai gambar (mould loft)

○ Tahap pendampingan (technical assistance)

Setelah mengikuti pelatihan peserta diminta untuk menerapkan metode 
yang telah mereka pelajari tentang mould loft dan membaca gambar kerja di tempat mereka bekerja. Pendampingan dilakukan melalui kunjungan ke tempat mitra secara berkala, serta memberikan waktu konsultasi pada peserta

\section{- Tahap evaluasi akhir}

Pada tahap ini peserta diberi tes sumatif untuk mengukur seberapa jauh daya serap mereka terhadap pelatihan ini. Sehingga kegiatan ini dapat terukur tingkat keberhasilannya

\section{PELAKSANAAN KEGIATAN}

\subsection{Pelatihan}

"Pelatihan Mould Loft (Lantai Gambar) Kapal bagi Pengrajin / Pembuat Kapal Tradisional di Kabupaten Batang - Jawa Tengah" sebagai Khalayak Sasaran, memiliki manfaat sebagai berikut :

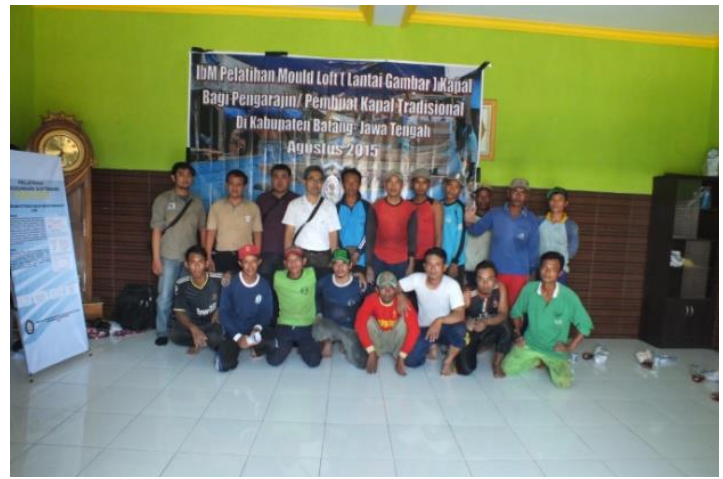

Gambar 4. Pelatihan Mould Loft

- Bertambahnya kemampuan dan ketrampilan para pengrajin/ pembuat kapal tradisional di CV. Laksana Abadi dan CV. Rizki Maulana Bahari dalam hal mould loft kapal pada lantai gambar yang meliputi :

a. Cara penggambaran Rencana Garis dengan ukuran sebenarnya ( skala 1:1 )

b. Membuat garis bentuk gading pada body plan.

c. Membuat garis lengkung geladak melintang pada body plan.

d. Membuat garis lengkung geladak memanjang pada gambar pandangan samping (sheer plan).

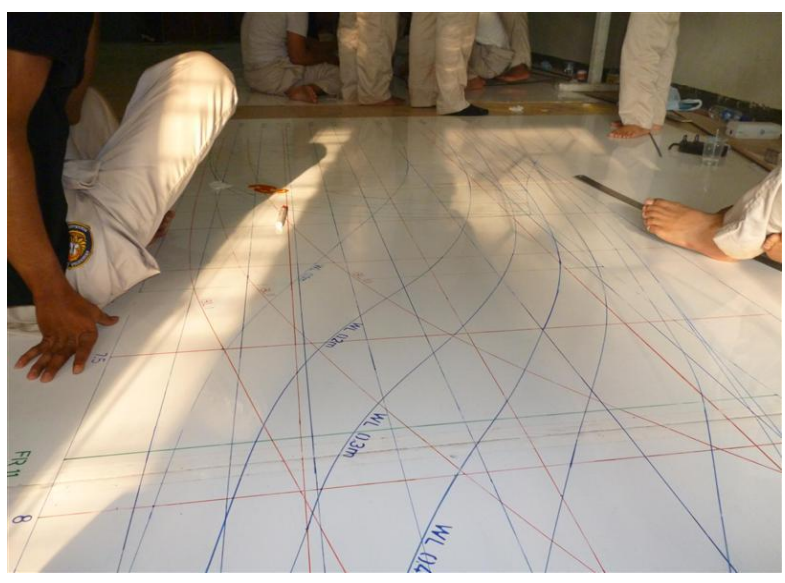

Gambar 5. Pelatihan membuat gambar kerja ke skala $1: 1$.

- Bertambahnya kemampuan dan ketrampilan para pengrajin/ pembuat kapal tradisional dalam hal membaca gambar kerja dalam pembangunan kapal, sehinnga mampu meningkatkan mutu dari produksi kapal yang dibangun.

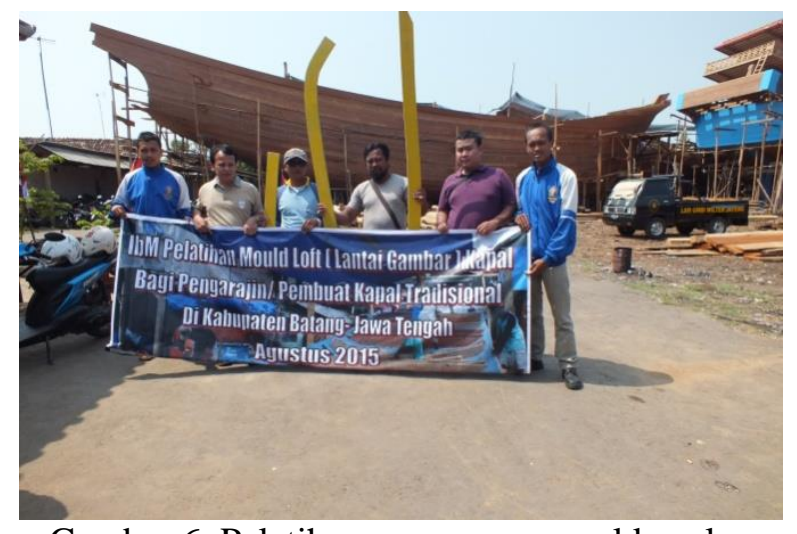

Gambar 6. Pelatihan penggunaan mal kapal

\subsection{Proses Mould Loft}

Mould loft adalah menggambar bentuk badan kapal maupun dalam skala 1:1 pada lantai gambar, meliputi gambar seluruh gadinggading kapal dan perletakan senta, serta gambar bentangan dari pelat kapal.

\section{Fasilitas yang dibutuhkan:}

1. Sebuah lantai gambar yang terbuat dari papan dengan dasar warna yang agak gelap, misalnya hijau dan harus terlindungi dalam gedung.

2. Material-material pembuat rambu, yang biasa dipakai adalah kayu plywood, 
tripleks, kertas film/transparan dan bilah kayu yang mudah dilengkungkan.

3. Besi dan ganjal pemberat.

4. Alat-alat gambar misalnya penggaris, jangka, meteran dll.

5. Sipatan, yaitu benang yang dipergunakan untuk membuat garis lurus dengan cara menghentakkannya, sehingga akan meninggalkan suatu garis lurus karena benang diberi zat pewarna (cairan lem putih atau warna lain).

6. Alat tulis cairan pewarna.

7. Alat-alat perkayuan misalnya mesin bor, mesin potong, palu dan paku.

\section{Tujuan Penggambaran Skala 1:1}

Dengan tergambarnya bentuk badan kapal/konstruksi kapal dalam skala 1:1 maka akan didapat bentuk badan kapal yang akurat dan ukuran konstruksi kapal yang tepat, sehingga dalam proses pembangunannya segala ukuran yang terpakai sudah tepat dan tidak ada kesalahan bentuk maupun ukuran. Hal ini sangat diperlukan oleh pihak pelaksana, untuk menunjang kemudahan pelaksanaan dan kualitas hasil pekerjaan.

Dari hasil penggambaran berupa bentukbentuk dan ukuran yang sebenarnya, akan dipindahkan dalam bentuk mal/template yang lengkap dengan data-data ukuran serta datadata yang lainnya, yang akan diserahkan ke bagaian fabrikasi untuk dibuatkan komponenkomponen sesuai bentuk dan ukuran pada template masing -masing. Dalam penggambaran bentuk badan kapal sesungguhnya, tidak selalu sepanjang ukuran kapal seluruhnya, terutama untuk daerah tengah (parallel middle body). Hal ini dilakukan untuk penghematan tempat, pekerjaan. Dapat pula gambar-gambar digambar secara menumpuk, untuk mengatasi kesulitan membaca gambar yang menumpuk maka digunakan warna cat yang berbeda.

\section{Gambar-gambar pada mould loft:}

1. Lines plan.

2. Bentangan/bukaan kulit.

3. Segala detail konstruksi yang diperlukan.

4. Dan gambar lain yang dianggap diperlukan, karena kesulitan pembuatan mal bila tidak disediakan gambar ukuran sebenarnya.

\section{HASIL KEGIATAN}

Pelatihan Mould loft:

\section{Struktural Body Plan}

Yaitu membuat ulang gambar body plan dengan skala 1:1 di atas lantai gambar (shop floor), dengan tujuan untuk memudahkan pekerjaan moulding yang lain seperti pembuatan rambu atau mal.

Data yang dibutuhkan dalam adalah :

- Lines plan dan body plan

- Offset table berisi half breadth plan

Peralatan yang digunakan antara lain : Kayu struklat, pemberat struklat, penggaris, jangka, benang sipatan, alat tulis, rol meteran, mal kapal ukuran 1:1 dari plat strip

Proses pengerjaan vertical body plan pada lantai gambar :

1. Membuat garis tegak lurus, yakni vertical dan horizontal

2. Pembacaan half breadth plan berdasarkan offset table

3. Kemudian menggambar body plan dengan skala 1:1

4. Menggambar sheer plan, jika luas lantai gambarnya terbatas maka hanya digambar haluan dan buritannya saja

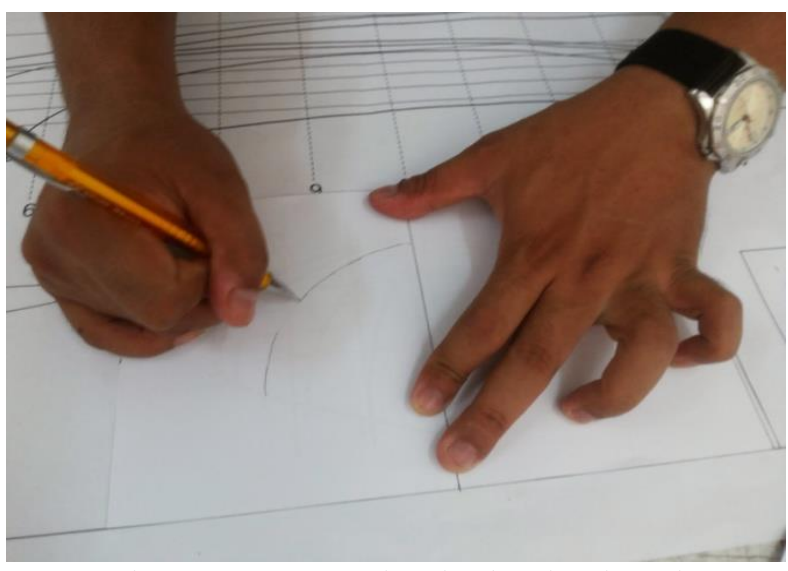

Gambar 7. Menggambar body plan kapal

\section{Marking List}

Adalah tabel yang berisi tentang daftar gambar komponen-komponen konstruksi untuk kemudian diserahkan di bagian fabrikasi.

Data yang dibutuhkan untuk membuat marking list :

1. Working drawing

2. Material list 
3. Lines plan dan body plan

Peralatan yang digunakan, antara lain :

- penggaris,

- pensil

- penghapus

Proses pembuatan marking list adalah :

1. Pemberian tanda ukuran komponen yang teratur pada working drawing

2. Pengecekan hasil 1. disesuaikan dengan keadaan body plan yang ada di lantai gambar

3. Menggambar ulang komponenkomponen konstruksi tersebut pada kertas marking list, disertai dengan pemberian informasi berupa jenis material, nama komponen, ukuran-ukuran, posisi bagian dan lain-lain.

4. Pengecekan ulang

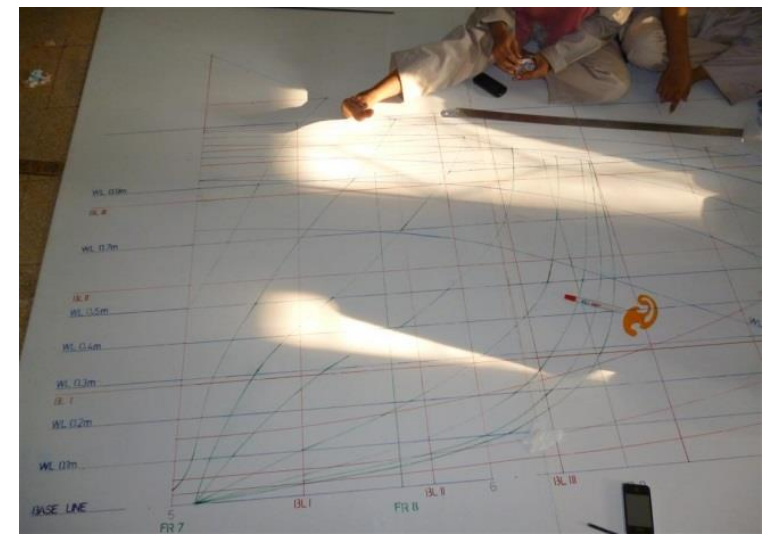

Gambar 8. Marking list body plan kapal

\section{Rambu Bending Kayu}

Adalah bentuk yang digunakan sebagai patokan dalam membuat lengkungan, bisanya berasal dari kayu meranti (dengan ukuran $6 \mathrm{~mm}$ x $60 \mathrm{~mm}$ x $4000 \mathrm{~mm}$ ).

Data yang dibutuhkan adalah :

- Working drawing

- Marking list

- Lines plan dan body plan

Peralatan yang digunakan antara lain : kayu meranti ukuran $6 \mathrm{~mm}$ x $60 \mathrm{~mm} \times$ $4000 \mathrm{~mm}$, Struklat dan pemberatnya, mal kapal ukuran 1:1, paku, palu, alat tulis, film polyster, penggaris.

Proses pembuatan rambu kayu adalah
1. Menggambar ulang body plan yang akan dibuat rambu bending ke film polyster

2. Dari film polyster kemudian dipindahkan ke kayu dengan cara dimal dan diberi marking diatas kayu

3. Pemotongan kayu tersebut sesuai dengan tanda marking

4. Hasil potongan dihaluskan dan dirakit menjadi satu sehingga membentuk rambu kayu

5. Memberikan tanda marking yang meliputi coding, posisi, nama bagian, ukuran material, jenis material, straight line dan lain-lain

6. Merakit rambu kayu-rambu kayu dengan posisi berurutan, sesuai letak frame dan garis straight line harus lurus

7. Pengecekan ulang

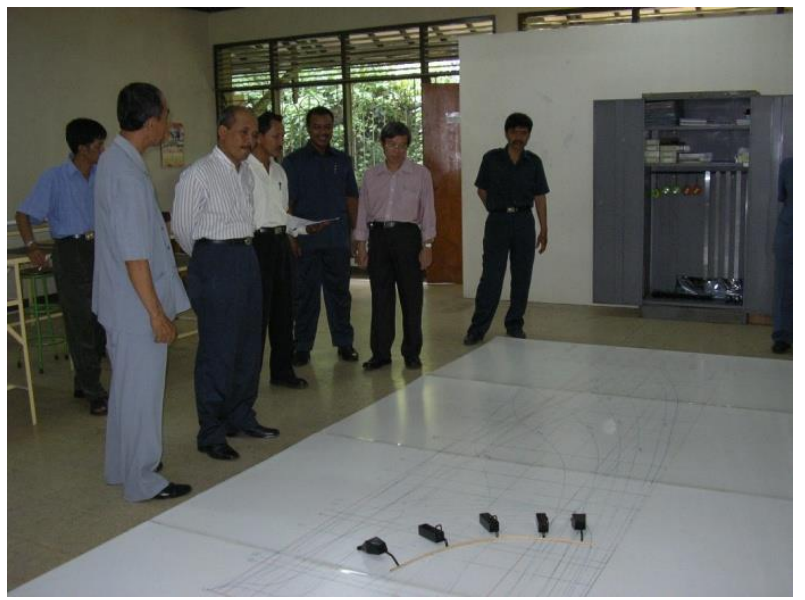

Gambar 9. Proses pembuatan lantai gambar kapal

\section{Cutting Plan}

Adalah pembuatan gambar rinci/detail, shell dan nesting dengan bantuan komputer sehingga dihasilkan gambar rencana potong plat untuk mesin $\mathrm{CNC}$ (mesin potong otomatis.

Tahap pengerjaan dalam membuat cutting plan, adalah :

1. Pembuatan gambar rinci (detail drawing), shell dan profile sesuai dengan working drawing

2. Melakukan nesting secara optimal agar diperoleh rencana potong optimal dengan sisa plat yang sedikit 
3. Membuat program pemotongan dengan NC

4. Pengecekan melalui replay dan simultan drawing

5. Mengcopy ke disket, paper tape dan table curve

6. Mengeplot gambar rencana potongan

\section{KESIMPULAN DAN SARAN}

\subsection{Kesimpulan}

Pelatihan teknik mould loft (lantai gambar) kapal bagi pengrajin/pembuat kapal tradisional (CV. Laksana Abadi dan CV. Rizky Maulana Bahari) di kabupaten Batang telah dilaksanakan dengan baik. Dari hasil evaluasi menunjukkan telah terjadi peningkatan kemampuan sebesar $25 \%$ dari kemampuan sebelumnya. Hal ini berarti bahwa pelatihan terbukti dapat meningkatkan pengetahuan dan ketrampilan para pengrajin kapal tradisional dalam hal teknik membentuk lengkungan bentuk lambung kapal dengan bantuan mould loft dan mal rambu kayu yang telah diberikan kepada mirta.

\subsection{Saran}

Melihat hasil peningkatan yang kurang signifikan, maka sebaiknya peserta pelatihan adalah peserta yang benar-benar memiliki latar belakang pendidikan teknik minimal setara dengan STM, karena dalam pelatihan ini sangat dibutuhkan pengetahuan untuk memahami dan membaca gambar.

\section{DAFTAR PUSTAKA}

[1] Ari. B.S, Eko Sasmito Hadi, Parlindungan Manik, 2006, Kajian Stabilitas Kapal Ikan type purse seine di Kabupaten Batang. Majalah Kapal Vol III no 1 Hal 10 - 16. Fakultas Teknik - Universitas Diponegoro Indonesia.

[2] Parlindungan Manik, Eko Sasmito Hadi, 2007, Design Kapal Ikan Tradisional type Batang dengan Penggerak Layar dan Motor (Project Design KLM Torani II). Majalah Kapal Vol IV no 1 hal $16-25$. Fakultas Teknik - Universitas Diponegoro - Indonesia.
[3] Ari. B. S, Eko Sasmito Hadi, Parlindungan Manik, 2007, Kajian parameter hydrostatis dan Stabilitas pada bagan apung di Kabupaten Rembang. Majalah Kapal Vol IV no 2 hal 79 - 86. Fakultas Teknik Universitas Diponegoro - Indonesia.

[4] Ari Gudmundsson, 2009, "Safety practices related to small fishing vessel stability", Fishing Technology Service Fish Products and Industry Division FAO, Rome.

[5] Captain Barb Howe, M.Ed, 2000," Fishing Vessel Stability - Proving The Principles", Workers' Compensation Board of British Columbia, Publications \& Videos Department, 6711 Elmbridge Way, Richmond, BC V7C 4N1Jan Fredrik Frantzen, 2006, "More fishing vessels needed", Buletin Fiskeriforskning Info, No 10 Nopember 2006. Norway.

[6] S.K. Lee, et all, 2005 ,’Roll performance of a small fishing vessel with live fish tank", Ocean Engineering Volume 32, Issues 14-15, October 2005, Pages 1873-1885

[7] UNOLS (University - National Oceanographic Laboratory System),2009, "Research Vessel Safety Standards", UNOLS RVSS Ninth Edition - March 2009, University of Rhode Island - Graduate School of Oceanography 15 South Ferry Road Narragansett, RI 02882. 